\title{
Philosophiques
}

\section{La philosophie institutionnelle : critique et/ou idéologie?}

Présentation

\section{Robert Nadeau}

Volume 3, numéro 1, avril 1976

URI : https://id.erudit.org/iderudit/203045ar

DOI : https://doi.org/10.7202/203045ar

Aller au sommaire du numéro

Éditeur(s)

Société de philosophie du Québec

ISSN

0316-2923 (imprimé)

1492-1391 (numérique)

Découvrir la revue

Citer ce document

Nadeau, R. (1976). La philosophie institutionnelle : critique et/ou idéologie? Présentation. Philosophiques, 3(1), 93-93. https://doi.org/10.7202/203045ar d'utilisation que vous pouvez consulter en ligne.

https://apropos.erudit.org/fr/usagers/politique-dutilisation/ 


\title{
INTERVENTIONS
}

\author{
Première Partie
}

\section{LA PHILOSOPHIE INSTITUTIONNELLE : CRITIQUE ET/OU IDÉOLOGIE ?}

Les premier et deux novembre derniers, la Société de Philosophie du Québec organisait à Montréal, au Cegep de Maisonneuve, un congrès sur «la situation institutionnelle de la philosophie au Québec ». On trouvera, dans le volume 2, no 1 du Bulletin de la S.P.Q., le programme complet et, dans le volume 2, no 2, un ensemble de documents provenant de ce congrès spécial, dont les propositions adoptées par l'Assemblée générale ainsi que les rapports des ateliers de travail qui s'y sont tenus.

En première partie de la rubrique «Interventions», nous présentons les textes des trois participants à une table ronde organisée dans le cadre de ce même congrès. Cette table ronde eut lieu le dimanche 2 novembre, chacun des panelistes devant prendre position sur la question: « La philosophie institutionnelle : critique et/ou idéologie? $\gg$.Cette table ronde, animée par Claude Panaccio du Département de Philosophie de l'Université du Québec à Trois-Rivières, a réuni MM. Jean-Guy Daoust, directeur du Département de Philosophie du Cegep de Maisonneuve, Jean Proulx, du Cegep Ahuntsic et ex-directeur de la Coordination provinciale de l'enseignement de la philosophie au niveau collégial, ainsi que Jean-Paul Brodeur, directeur du programme de maitrise au Département de Philosophie de l'Université du Québec à Montréal 